\title{
Pengaruh Emo Demo Terhadap Pemberian Menu MP ASI Pada BADUTA
}

\section{The Influence Of Emo Demo Against Provision Of MP ASI Menu on BADUTA}

\author{
Muthmainnah Zakiyyah ${ }^{1}$, Mega Silvian Natalia, Tutik Ekasari \\ Prodi DIII Kebidanan STIKES Hafshawaty \\ ${ }^{1}$ Email: iinlira20@gmail.com
}

\begin{abstract}
ABSTRAK
Emo Demo atau Emotional Demonstration adalah kegiatan aktif berbasis pada perubahan perilaku pada kelompok masyarakat target (ibu hamil dan ibu menyusui) yang dikembangkan oleh Global Alliance for Improved Nutrition (GAIN). Makanan pendamping ASI (MPASI) merupakan makanan peralihan dari ASI ke makanan keluarga yang mengandung zat gizi, diberikan pada anak berumur 6-24 bulan untuk memenuhi kebutuhan gizinya selain dari ASI. Pada tahun 2018 proporsi konsumsi makanan beragam pada anak usia 6-23 bulan di Propinsi Jawa Timur sebesar 46,6\%. Hal ini masih di bawah target pemerintah yaitu 52\%. Berdasarkan survey pendahuluan yang dilakukan pada tanggal 24 Desember 2018 kepada 10 BADUTA, 5 diantaranya mendapat menu berupa nasi saja, 3 BADUTA diberikan nasi dan sayuran, dan 2 lainnya berupa nasi, sayuran dan lauk. Oleh karena itu, tujuan penelitian ini adalah untuk mengetahui pengaruh emo demo terhadap pemberian menu MPASI pada BADUTA. Metode penelitian ini menggunakan analitik dengan rancang bangun cross sectional. Teknik pengambilan sampel dengan simple random sampling, yakni 46 orang ibu yang mempunyai BADUTA. Uji statistik yang digunakan adalah Chi Square. Hasil uji statistik diperoleh nilai $\mathrm{p}=0,003$ sehingga dapat diartikan bahwa ada Pengaruh Emo Demo terhadap pemberian menu MPASI pada BADUTA.
\end{abstract}

Kata Kunci : Emo Demo, Menu, Makanan Pendamping ASI.

\section{ABSTRACT}

Emo Demo or Emotional Demonstration is an active activity based on behavior change in the target community groups (pregnant women and nursing mothers) developed by the Global Alliance for Improved Nutrition (GAIN). ASI complementary food (MPASI) is a food transition from breast milk to family foods that contain nutrients, given to children aged 6-24 months to meet their nutritional needs other than breast milk. In 2018 the proportion of food consumption varies among children aged 6-23 months in East Java Province by 46.6\%. This is still below the government's target of 52\%. Based on a preliminary survey conducted on December 24, 2018 to 10 BADUTA, 5 of whom received menus in the form of rice only, 3 BADUTA were given rice and vegetables, and 2 others in the form of rice, vegetables and side dishes. Therefore, the purpose of this study was to determine the effect of the emo demo on giving the MPASI menu to BADUTA. This research method used analytic with cross sectional design. The sampling technique was simple random sampling, which is 46 mothers who had BADUTA. The statistical test used Chi Square. The statistical test resulted obtained $p$ value $=0.003$ so that it can be interpreted that there was the Effect of Emo Demo on giving the MPASI menu to BADUTA.

Keywords: Emo Demo, Menu, ASI Complementary Food.

\section{PENDAHULUAN}

Emo Demo merupakan sesi

edukasi interaktif menggunakan

permainanantara individu, kelompok

atau masyarakat dengan melibatkan psikologis individu dalam mengembangkan strategi komunikasi untuk mencapai perubahan perilaku secara positifdalamPemberian Makan Bayi dan Anak (PMBA) sesuai dengan 
tahapan tumbuh kembang anak(Admin, 2017).

Makanan pendamping ASI (MPASI) merupakan makanan transisi dari ASI ke makanan semi padat yang mengandung zat gizi, diberikan pada anak berumur 6-24 bulan untuk memenuhi kebutuhan gizinya selain dari ASI. Tujuan makanan pendamping ASI (MPASI) sebagai pelengkap dari ASI. Pengenalan dan pemberian MPASI harus dilakukan secara bertahap baik bentuk maupun jumlahnya, sesuai dengan kemampuan pencernaan bayi/anak (Mufida, 2015).

Pada tahun 2018 proporsi konsumsi makanan beragam pada anak usia 6-23 bulan di Propinsi Jawa Timur sebesar 46,6\%. Hal ini masih di bawah target pemerintah yaitu 52\%. Ada 18 desa lokus program pencegahan dan penanggulangan stunting di Kabupaten Probolinggo, salah satunya adalah Desa Gebangan Kecamatan Krejengan. Desa Gebangan Kecamatan Krejengan mempunyai kasus stunting sebanyak 133 (Riskesdas, 2018). Berdasarkan survey pendahuluan yang dilakukan oleh peneliti pada tanggal 24 Desember 2018 di Desa Gebangan Kecamatan Krejengan kepada 10 BADUTA didapatkan 5 BADUTA menu MP ASI yaitu berupa nasi saja, 3 BADUTA menu MP ASI yaitu berupa nasi dan sayuran dan 2 BADUTA menu MP ASI berupa nasi, sayuran dan lauk.

"Emo Demo"merupakan salah satu teknik promosi kesehatan. Kekuatan emosional yang digunakan dalam kegiatan demonstrasi. Pelaksanaan penyuluhan emo demo dilakukan dengan sederhana, membutuhkan waktu hanya 15-20 menit. Penyuluhan Emo Demo ini diberikan kepada ibu yang mempunyai BADUTA melalui gameseru, peragaan, dan nonton film. Salah satu modul emo demo yaitu ATIKA (Ati, Telur, Ikan) yang harus dikonsumsi oleh BADUTA.Modul itu diberikan agar para ibu yang mempunyai BADUTA selalu memberikan menu konsumsi makanan sehat tersebut untuk kesehatan BADUTA nya (Fansi, 2018).

\section{METODE PENELITIAN}

Penelitian ini merupakan penelitian analitik yang menjelaskan Pengaruh antar variable dengan menggunakan alat bantuberupa kuesioner untuk mengukur setiap variabel yang diteliti. Rancang bangun penelitian ini adalah cross sectional. Variabelpenelitiandiukurdalamsuatuwak 
tusehinggadiperoleh gambaran keadaan pada waktu tersebut. Penelitian inidilakukan di Desa Gebangan Kecamatan Krejengan. Populasi pada penelitian ini adalah semua ibu yang mempunyai BADUTA yaitu sebanyak 52 orang. Teknik sampling dalam penelitian ini menggunakan simpel random sampling. Sampel: Sebagian ibu ha ibu yang mempunyai BADUTA yaitusebanyak 46 orang. Pengumpulan data dengan menggunakan kuesioner dan dianalisa dengan univariat, bivariat dengan chi-square dengan bantuan SPSS.

\section{HASIL DAN PEMBAHASAN}

Analisis univariat

1. Keikutsertaan Emo Demo

Tabel 1 Distribusi Keikutsertaan Emo Demo di Desa Gebangan Tahun 2019.

\begin{tabular}{lcc}
\hline Variabel & Frekuensi & Persentasi \% \\
\hline Mengikuti & 39 & 84,8 \\
Tidak Mengikuti & 7 & 15,2 \\
Total & $\mathbf{4 6}$ & $\mathbf{1 0 0}$ \\
\hline
\end{tabular}

Berdasarkan tabel 1 menunjukkan bahwa sebagian besar responden sudah mengikutiEmo Demo yaitu sejumlah 39 responden $(84,8 \%)$.

2. Pemberian menu MP ASI

Tabel 2 Distribusi Pemberian Menu MP Asi di Desa Gebangan Tahun 2019.

\begin{tabular}{lcc}
\hline \multicolumn{1}{c}{ Variabel } & Frekuensi & Persentasi \% \\
\hline Baik & 35 & 76 \\
Cukup & 6 & 13 \\
Kurang & 5 & 11 \\
Total & $\mathbf{4 6}$ & $\mathbf{1 0 0}$ \\
\hline
\end{tabular}

Berdasarkan tabel

menunjukkan bahwa sebagian besar responden sudah baik dalam memberikan menu MP ASI yaitu sejumlah 35 responden $(76 \%)$.

Analisis bivariat

Pengaruh Emo Demo Terhadap Pemberian Menu MP Asi pada BADUTA sebagaimana tabel berikut:

Tabel 3 Tabulasi Silang Pengaruh Emo Demo Terhadap Pemberian Menu MP Asi pada BADUTA.

\begin{tabular}{|c|c|c|c|c|c|c|c|}
\hline \multirow{3}{*}{ Menu MP ASI } & \multicolumn{6}{|c|}{ Keikutsertaan Emo Demo } & \multirow{3}{*}{ P Value } \\
\hline & \multicolumn{2}{|c|}{ Mengikuti } & \multicolumn{2}{|c|}{ Tidak mengikuti } & \multicolumn{2}{|c|}{ Total } & \\
\hline & $\mathbf{N}$ & $(\%)$ & $\mathbf{n}$ & $(\%)$ & $\mathbf{n}$ & $(\%)$ & \\
\hline Baik & 33 & 84,6 & 2 & 28,6 & 35 & 76 & $\mathbf{0 , 0 0 3}$ \\
\hline Cukup & 4 & 10,3 & 2 & 28,6 & 6 & 13 & \\
\hline Kurang & 2 & 5,1 & 3 & 42,8 & 5 & 11 & \\
\hline Total & 39 & 100 & 7 & 100 & 46 & 100 & \\
\hline
\end{tabular}

Berdasarkan dari analisis bivariat menunjukkan bahwa dari 39 responden terdapat $33(84,6 \%)$ sudah mengikuti emo demo dan sudah baik dalam 
memberikan menu MP Asi, sedangkan terdapat $2(5,1 \%)$ responden sudah mengikuti emo demo akan tetapi masih kurang dalam memberikan menu MP Asi. Hasil uji statistik diperoleh nilai $\mathrm{P}$ value $=0,003$ sehingga dapat diartikan bahwa ada hubungan antara Emo Demo dengan pemberian menu MP ASI.

Pada periode ini pertumbuhan fisik dan perkembangan kecerdasan anak sangat pesat sehingga selain kualitas dan kuantitas pemberian MP ASI, hygienitas juga sangat penting diperhatikan dalam pemberian MP ASI tersebut. Sanitasi dan hygienitas MP ASI yang buruk bisa mengakibatkan kontaminasi mikroba sehingga dapat meningkatkan resiko terjadinya infeksi lain pada bayi. Dalam kurun waktu 6 bulan pertama pemberian ASI masih bisa mencukupi kebutuhan gizi bayi, akan tetapi setelah 6 bulan produksi ASI akan menurun yang dapat mengakibatkan kecukupan gizi bayi tidak terpenuhi hanya dengan pemberian ASI saja. Oleh sebab itu pemberian makanan tambahan pada bayi umur diatas 6 bulan peranannya sangat penting untuk memenuhi kebutuhan gizi pada bayi tesebut (Mufida, 2015).
Pada prinsipnya makanan tambahan untuk bayi atau yang biasa dikenal sebagai makanan pendamping ASI (MP-ASI) merupakan makanan yang banyak mengandung zat gizi, mudah dicerna, mudah disajikan, mudah disimpan, hygienis dan harganya mudah dijangkau. Makanan tambahan pada bayi bisa berupa campuran dari berbagai bahan makanan yang perbandingannya sudah disesuaikan agar diperoleh makanan dengan gizi yang tinggi (Purnamasari, 2014).

Emo Demo merupakan salah satu teknik promosi kesehatan yang dilakukan dengan cara demonstrasi menggunakan kekuatan emosional. Pelaksanaan penyuluhan dengan teknik emo demo dilakukan dengan sederhana, waktu yang dibutuhkan hanya 15-20 menit. Kegiatan itu diberikan kepada ibu yang mempunyai BADUTA melalui gameseru, peragaan, dan nonton film. Salah satu modul emo demo yaitu ATIKA (Ati, Telur, Ikan) yang harus dikonsumsi oleh BADUTA. Modul itu diberikan agar para ibu yang mempunyai BADUTA selalu memberikan menu konsumsi makanan sehat tersebut untuk kesehatan BADUTA nya (Fansi, 2018). 
Metode Emo Demo selain memberikan informasi kesehatan juga menggunggah emosi yang dimiliki subjek sehingga subjek tersebut akan terdorong untuk melakukan perubahan perilaku. Rasa jijik merupakan salah satu emosional yang dapat dibangkitkan untuk mengubah perilaku subjek penelitian. Seorang individu secara alamiah pasti akan menghindari ancaman yang bersifat menyakitkan dan atau menjijikkan (Leontsini dkk. 2014).

Emotional Demonstration (Emo Demo) adalah salah satu metode edukasi masyarakat yang dikembangkan oleh Global Alliance for Improved Nutrition (GAIN) melalui pendekatan baru yang mengacu pada teori Behavior Centered Design (BCD). BCD dicetuskan oleh Environmental Health Group dari London School of Hygiene and Tropical Medicine (LSHTM). BCD dikembangkan berdasarkan prinsip evolusioner dan psikologi lingkungan sekaligus juga sebagai cara untuk merencanakan dan menguji intervensi perubahan perilaku yang bersifat imajinatif dan provokatif. Teori BCD berprinsip bahwa perilaku hanya dapat berubah sebagai respon atas sesuatu yang baru, menantang, mengejutkan atau menarik. Metode
Emo Demo ini menggunakan cara-cara yang bersifat imajinatif dan provokatif untuk mencapai perubahan perilaku dalam bidang kesehatan masyarakat (Amareta, 2018).

Hasil penelitian menunjukkan terdapat hubungan antara Emo Demo dengan pemberian menu MP ASI pada BADUTA. Hal tersebut sejalan dengan penelitian yang dilakukan oleh Dahlia dkk 2017 didapatkan hasil uji statistic menunjukkan ada perbedaan yang signifikan pada pengetahuan responden setelah diberikan intervensi $\mathrm{p}$ value $=$ 0,000 dengan $\alpha=0,05$. Artinya penyuluhan kesehatan dengan metode Emo Demo berhasil meningkatkan pengatahuan secara signifikan. Begitu pula pada praktik responden yang menunjukkan adanya perbedaan setelah diberikan intervensi ( $\mathrm{p}$ value $=$ 0,000).Hasil penelitian ini membuktikan bahwa penyuluhan dengan metode Emo Demo berhasil meningkatkan pengetahuan dan praktik (Dahlia dkk, 2017). 


\section{SIMPULAN DAN SARAN}

Berdasarakan hasil analisis bivariat bahwa dari 39 responden terdapat $33(84,6 \%)$ sudah mengikuti emo demo dan sudah baik dalam memberikan menu MP Asi, sedangkan terdapat $2(5,1 \%)$ responden sudah mengikuti emo demo akan tetapi masih kurang dalam memberikan menu MP Asi. Hasil uji statistik diperoleh nilai $\mathrm{p}$ $=0,003$ sehingga dapat diartikan bahwa ada hubungan antara Emo Demo dengan pemberian menu MP ASI.

Mengadakan forum belajar yang akan mengawal pelaksanaan Emo Demo sehingga ketika ada persoalan ada tempat untuk berdiskusi, diperlukan komitmen dinas kesehatan untuk memasukan dalam integrasi Taman posyandu.

\section{DAFTAR PUSTAKA}

Admin Gizi. 2017. Workshop emo demo jurusan gizi fakultas kedokteran universitas brawijaya. http://gizi.fk.ub.ac.id/workshopemo-demo-jurusan-gizi-fakultaskedokteran-universitasbrawijaya/. Diaksestanggal 30 Desember 2018.

Amareta, Dahlia. 2018. Peningkatan Praktik Cuci Tangan Pakai Sabun pada Anak Usia Sekolah dengan Metode Emo Demo. Jurnal Keperawatan.Vol. 4 No.2 Hal. 122-130.

Dahlia dan Efri. 2017. Penyuluhan Kesehatan dengan Metode Emo Demo Efektif Meningkatkan Praktik CTPS di MI Al-Badri Kalisat Kabupaten Jember. Seminar Nasional Hasil Penelitian 2017. ISBN : 978-602-14917-5-1

Fansi Perdana Putri. 2018. Ajarkan Calon trainer 12 modul emo demo.

http://dinkes.surabaya.go.id/portal /berita/ajarkan-calon-trainer-12modul-emo-demo/. Di akses tanggal 30 desember 2018.

Mufida. 2015. Prinsip Dasar MPASI Untuk Bayi Usia 6-24 Bulan. Jurnal Pangan dan Agroindustri Vol. 3 No 4 p.1646-1651.

Purnamasari dan Wulandari Eka. 2014. Optimasi Kadar Kalori Dalam Makanan Pendamping ASI (MPASI). Jurnal Pangan dan Agroindustri. Vol.2 No.3 p.19-27 